\title{
O OFÍCIO DO HISTORIADOR: A ÉTICA EM PESQUISAS COM FONTES HISTÓRICAS
}

The Office of the historian: ethics in research with historical sources

El oficio del historiador: la ética en investigaciones con fuentes históricas

Received: november/2020

Accepted: december $/ 2020$

Available online: december/2020

Mário Allan da Silva Lopes, Doutorando em Educação, Universidade do Estado do Pará, Brasil

E-mail: marioallan19@yahoo.com.br

Resumo: Este ensaio tem por objetivo discutir uma visão de ética presente na obra Apologia da História ou o Ofício do Historiador, de Marc Bloch e como ele a apresenta em seu livro. Marc Bloch foi um historiador francês notável e de grande contribuição para o novo fazer histórico. Ele inovou ao analisar a história a partir de uma nova perspectiva, não mais utilizando as fontes como verdade, mas sim como um dos elementos que compõem a pesquisa histórica. A história nova não se preocupava mais apenas com os grandes heróis, com as datas marcantes ou com os grandes impérios, agora o homem comum também era fonte para a história e para o entendimento da sociedade. Em Bloch a ética se apresenta de maneira bem significativa, para o autor a pesquisa histórica não deve ser apenas científica, mas também preocupar-se com a moral e a civilidade.

Palavras-chave: Marc Bloch, Ética, História, Fonte.

Abstract: This essay aims to discuss a vision of ethics present in Marc Bloch's Apology of History or the Office of the Historian and how he presents it in his book. Marc Bloch was a notable French historian and a major contributor to the new historical making. He innovated analyzing history from a new perspective, no longer using sources as truth, but as one of the elements that make up historical research. The new story no longer concerned only with the great heroes, with the milestones or with the great empires, now the common man was also a source for history and for the understanding of society. In Bloch ethics presents itself in a very significant way, for the author historical research should not only be scientific, but also concern himself with morality and civility. 
Resumen: Este ensayo tiene por objeto discutir una visión de ética presente en la obra Apología de la Historia o el Oficio del Historiador, de Marc Bloch y como él la presenta en su libro. Marc Bloch fue un historiador francés notable y de gran contribución para el nuevo hacer histórico. Ha innovado analizar la historia desde una nueva perspectiva, ya no utilizando las fuentes como verdad, sino como uno de los elementos que componen la investigación histórica. La historia nueva no se preocupaba más sólo de los grandes héroes, de las fechas marcantes o de los grandes imperios, ahora el hombre común también era fuente para la historia y para el entendimiento de la sociedad. En Bloch la ética se presenta de manera muy significativa, para el autor la investigación histórica no sólo debe ser científica, sino también preocuparse por la moral y la civilidad.

Palabras-clave: Marc Bloch, Ética, Historia, Fuente.

\section{INTRODUÇÃO}

Este ensaio nasce a partir de discussões sobre a ética e a pesquisa realizadas na disciplina Pesquisa em Educação, no doutorado do Programa de Pós-Graduação em Educação da Universidade do Estado do Pará. As discussões que iniciaram a partir de textos que discutiam as normas e ações dos Comitês de Ética da Pesquisa (CEP) em todo Brasil, levaram-nos a debater também acerca da ética enquanto postura individual do pesquisador para com sua pesquisa e para com os participantes.

Os debates sobre ética centram-se basicamente na pesquisa com seres humanos, ou como o Conselho Nacional de Saúde aborda: “amostras". Isso levou-me a refletir que ética é esta que norteia (ou deveria nortear) as pesquisas, principalmente as que se encontram no campo das Ciências Humanas? Será que realmente somos éticos ao realizar nossas pesquisas, para além da mera formalidade cobrada pelos CEPs?

E quanto à pesquisa histórica, que tem como uma de suas principais fontes documentos históricos como fotos, cartas, diários, livros, entre outros; documentos impressos, palpáveis que muitas das vezes foram redigidos por pessoas que já não se encontram vivos. Será que aí não há ética na pesquisa? 
Marc Bloch (2001), em seu livro Apologia da História ou o Ofício do Historiador nos mostra em seus escritos inacabados devido às maldades dos seres humanos (Bloch foi assassinado durante a segunda guerra mundial) que o fazer histórico, assim como o fazer dos pesquisadores das ciências humanas nunca estarão longe de um pensamento ético, que em Bloch (2001) remete-se à responsabilidade e a honestidade com as fontes, com a pesquisa, com os nossos pares científicos e, principalmente, com aqueles que lerão a nossa produção científica.

Ética vem do grego ethos, que significa de acordo com o Dicionário Online de Português (Dicio), um conjunto de características comuns a um grupo de indivíduos de uma mesma sociedade. Já o dicionário Michaelis Online traz o seguinte conceito:

1 Ramo da filosofia que tem por objetivo refletir sobre a essência dos princípios, valores e problemas fundamentais da moral, tais como a finalidade e o sentido da vida humana, a natureza do bem e do mal, os fundamentos da obrigação e do dever, tendo como base as normas consideradas universalmente válidas e que norteiam o comportamento humano (MICHAELIS ONLINE).

O que podemos perceber é que a ética, no sentido mais comum e usual da palavra, nos leva à dualidade do que é certo e errado, do que devemos ou não fazer, do que é obrigado ou não. Nos leva a caminhos de escolhas que podem prejudicar ou não os participantes da pesquisa ou a própria pesquisa, tudo dependerá dessas escolhas, da ética.

Diante deste debate, este ensaio vem com o intuito de discutir uma visão de ética presente na obra Apologia da História ou o Ofício do Historiador, de Marc Bloch e como ele a apresenta nos cinco capítulos de seu livro. Procuro debater para além das pesquisas de cunho histórico, mas também apresentando que a obra de Bloch pode (e deve) muito bem ser apreciada por pesquisadores de outras áreas, dada tamanha a riqueza que ele nos traz. Portanto discutiremos acerca da ética que podemos perceber na obra de Bloch, também dialogando com outros autores que colaborem no entendimento do texto e também de como estamos entendendo a história que o Bloch achava ser correta.

RBPPD/BRJPD | Vol. 2 | n. 4 | p. 265-277, 2020. 


\title{
O AUTOR, A OBRA E A ÉTICA
}

Marc Bloch foi um historiador francês nascido em 6 de julho de 1886, em Lyon, na França. Em sua carreira acadêmica estudou em Paris, Berlim e Leipzig. Foi pesquisador na Fundação Thiers, mas teve o trabalho interrompido devido a sua participação na Primeira Guerra Mundial. Também atuou na Segunda Guerra Mundial, fato que o levaria à morte, fuzilado pela Gestapo em 16 de junho de 1944.

Hoje é considerado um historiador muito importante para a mudança radical na forma de se escrever e de se entender a história. Foi um dos fundadores da Escola dos Annales, movimento de mudança historiográfica que se iniciou a partir do periódico francês Annales d'histoire économique et sociale (Anais de história econômica e social, em 1929).

\begin{abstract}
A vida de Marc Bloch foi caracterizada por um intenso trabalho, uma carreira universitária brilhante e uma destacada produção científica. É considerado o maior medievalista de todos os tempos e, para alguns, o maior historiador do século XX. Como um dos grandes responsáveis pela renovação do pensamento histórico, abriu novos horizontes para compreensão do feudalismo. Abandonou o caminho da História Tradicional de sequência de fatos com nomes e datas e se empenhou na construção de análises que consideram a complexa relação entre o homem, a sociedade e o tempo (GASPARETTO JUNIOR).
\end{abstract}

Escreveu obras de muita importância para a historiografia como os Reis Taumaturgos (1924) e A Sociedade Feudal (1939). Inovou ao observar em suas análises históricas para além do que a história tradicional abordava. Com o movimento da escola dos annales a história passa a ser vista da mesma forma que o ser humano é, um ser complexo e incompleto.

Essa nova maneira de escrever a história não mais preocupava-se apenas com os grandes heróis nacionais, homens de grande destaque, datas importantes ou com a história das grandes realezas e dos grandes impérios, agora ela iria mais fundo, observaria também o ser humano comum, seus fazeres, costumes, religiosidades, dentre outros, que também seriam de grande valor para o entendimento da sociedade. Com isso o entendimento de fontes históricas também se alargaria, não sendo considerado fonte apenas os documentos oficiais, mas também outras fontes, como objetos pessoais, cartas, imagens, literatura, entre outras. 
Por positivismo histórico, que era o alvo dos "annales", entende-se um tipo de visão do trabalho do historiador típico de uma corrente histórica também francesa, dominante no século XIX. Essa corrente entendia que ao historiador bastava expor as fontes escritas, sem necessidade de interrogar os documentos, de interpretá-los nas entrelinhas e de confrontá-los com outras fontes, como vestígios materiais arqueológicos etc. O modo de abordagem dos "annales", ao contrário, passou a valorizar essas outras fontes, além dos documentos escritos. Se hoje há a história do vestuário, do chiclete, das capas de discos de música, entre outros, isso se deve a esse esforço pela ampliação de análise que a Escola dos Annales desencadeou (FERNANDES).

Já o livro Apologia da História ou o Ofício do Historiador (1949, publicado por Lucien Febvre) trata das reflexões de Marc Bloch do que caracterizaria a profissão de historiador e qual a metodologia de trabalho deveria conduzir as pesquisas históricas. A capa da obra claramente remete aos estudos medievalistas, nos quais Bloch se especializou e inovou no campo historiográfico. O texto foi escrito enquanto ele estava na prisão na França pouco antes de ser executado e por isso mesmo é um ensaio incompleto.

Na obra podemos observar como Bloch entende a história: o ser humano no tempo, agindo, modificando, relacionando-se, vivendo em sociedade. Partindo deste princípio podemos entender que a história só existe quando há humanos interagindo. As pessoas fazem as histórias e as histórias também constroem as pessoas, logo, é um paradoxo.

Novos tempos levam a novas historicidades; boas perguntas constituem campos inesperados. Diante da insistência de Alice em saber qual a melhor formulação, assim reagia Humpty Dumpty, na famosa história de Lewi Carrol: “- A questão é: quem é o senhor, quem é o dono das perguntas?”. Nenhum objeto tem movimento na sociedade humana exceto pela significação que os homens lhe atribuem, e são as questões que condicionam o objeto e não o oposto (SCHWARCZ, 2001, p. 8).

Em toda obra podemos analisar a seriedade com a qual Bloch empregava o fazer histórico.

Não poderia ser um simples "narrar de fatos", mas assemelhava-se aos artesãos, que com calma, seriedade e compromisso, tecia as teias do tempo de forma responsável e ética. Para Bloch o fazer histórico não estava apenas atrelado a um fazer científico, mas também cívico e moral, como aponta Le Goff (2001, p. 17):

A própria expressão "legitimidade da história", empregada por Marc Bloch desde as primeiras linhas, mostra que para ele o problema epistemológico da história não é apenas um problema intelectual e científico, mas também um problema cívico e mesmo moral. O 
historiador tem responsabilidades e deve "prestar contas". Marc Bloch coloca assim o historiador entre os artesãos que devem dar provas de consciência profissional.

E assim podemos compreender um pouco mais da ética em Marc Bloch, para além das pesquisas históricas, as pesquisas científicas precisam assumir um caráter sério e de compromisso, não ficar preso apenas ao fazer científico, mas entender que estamos trabalhando para algo maior, a sociedade. O dever cívico e moral empregado por Le Goff em sua análise nos remete a esse ser ético que buscamos nas pesquisas.

\section{"PAPAI, ENTÃo ME EXPLICA PARA QUE SERVE A HISTÓRIA": A ÉTICA NA PRODUÇÃO HISTORIOGRÁFICA}

E é com esta frase que Marc Bloch inicia seu livro, uma pergunta feita por seu filho que desencadeou uma série de pensamentos filosóficos e intrigantes acerca do trabalho do historiador. Bloch deixa bem claro que o primeiro grande papel de um pesquisador/historiador é se fazer entender bem, tanto aos doutos quanto aos estudantes.

O livro faz jus àquela famosa frase do autor que diz: "saber falar, no mesmo tom, aos doutos e aos estudantes". Entendendo com isto que, fazer uma pesquisa é, principalmente produzir conhecimento, e este deverá estar ao alcance e compreensão de todos, não apenas a um grupo restrito de intelectuais (PEREIRA, 2017).

É perceptível na obra de Bloch que ele se preocupava em não cristalizar o conhecimento científico que ele produzia. Não era intenção dele produzir um conhecimento que ficasse girando em torno dos especialistas e que não servisse para a melhoria da sociedade. Portanto a história teria um grande papel no desenvolvimento do ser humano.

Não se pode negar, no entanto, que uma ciência nos parecerá sempre ter algo de incompleto se não nos ajudar, cedo ou tarde, a viver melhor. Em particular, como não experimentar com mais força esse sentimento em relação à história, ainda mais claramente predestinada, acredita-se, a trabalhar em benefício do homem na medida em que tem o próprio homem e seus atos como material? (BLOCH, 2001, p. 45).

RBPPD/BRJPD | Vol. 2 | n. 4 | p. 265-277, 2020. 
Bloch tira da história aquele caráter de verdade e de certeza. As fontes e os fatos precisam ser analisados, precisam ser problematizados, não podemos mais tratar a história como narração linear, fazendo-a cristalizada e tomando algumas poucas fontes como verdadeiras e passíveis de contar uma história com exatidão. Bloch nos deixa uma mensagem muito importante: nós nunca podemos chegar à verdade sobre um fato passado, mas as pesquisas históricas nos permitem aproximar-nos de determinado fato, a partir de determinada ótica.

E era contra essa "verdade" que Bloch contestava na ciência positivista. Como uma ciência se propunha a analisar a sociedade a partir de uma ótica científica padrão? Ele mesmo apontava toda a complexidade que circunda os seres humanos, que só uma ciência não seria capaz de tamanha façanha.

\begin{abstract}
O que Marc Bloch não aceitava em seu mestre Charles Seignobos, principal representante desses historiadores "positivistas", era iniciar o trabalho do historiador somente com a coleta dos fatos, ao passo que uma fase anterior essencial exige do historiador a consciência de que o fato histórico não é um fato "positivo", mas o produto de uma construção ativa de sua parte para transformar a fonte em documento e, em seguida, constituir esses documentos, esses fatos históricos, em problema (LE GOFF, 2001, p. 19).
\end{abstract}

E como aproximar-se do fato histórico? Como realizar uma pesquisa que pareça possível e cabível? Bloch nos chama a atenção para a importância de na história "recortar" um ponto particular, um ponto de aplicação. Imaginemos um historiador que se dedique a pesquisar o período colonial brasileiro, que podemos aqui inferir um período de mais de 200 anos. Este é um dos primeiros pontos de grande importância na pesquisa histórica: não se pode dar conta de tudo.

\footnotetext{
Não deixa de ser menos verdade que, face à imensa e confusa realidade, o historiador é necessariamente levado a nela recortar o ponto de aplicação particular de suas ferramentas; em consequência, a nela fazer uma escolha que, muito claramente, não é a mesma que a do biólogo, por exemplo; que será propriamente uma escolha do historiador. Este é um autêntico problema de ação (BLOCH, 2001, p. 52).
}

E dentro deste universo de fontes e fatos, o que de fato a história se preocupa são, como já mencionado, as pessoas e as suas interações. Sendo assim, onde entra a ação do homem, entra o 
interesse do historiador, portanto "o objeto da história é, por natureza, o homem. Digamos melhor: os homens" (BLOCH, 2001, p. 54).

Isso nos leva a refletir a seguinte afirmação: se a matéria principal da história são os seres humanos, então devemos sim ser éticos. Esses seres humanos podem contribuir com a pesquisas históricas através de relatos (vivos através da história oral) ou ainda através dos documentos, onde os seres humanos que nos antecederam continuam marcados. O que quero dizer com isto é que considero o documento ou a fonte histórica, tão viva quanto uma pessoa nos dias atuais. Tanto um quanto o outro são capazes de nos permitir aproximar de inúmeros momentos históricos da sociedade.

Julgo importante neste momento trazer uma grata diferenciação que Le Goff (2013) nos apresenta: documento e monumento. $\mathrm{O}$ monumento vem a ser a herança do passado e o documento é a escolha do historiador. O monumento parece estar ligado ao "poder de perpetuação, voluntária ou involuntária, das sociedades históricas" (LE GOFF, 2013, p. 486), já o documento remete a uma prova histórica, como um testemunho escrito.

Esse caráter de "prova histórica" é o que durante muito tempo serviu de verdade, como já dito anteriormente, para a história positivista. E é a partir deste pensamento e da definição elencada por Le Goff (2013) que entendemos outro ponto crucial para percebermos a ética em Bloch: a utilização responsável das fontes/documentos históricos.

Seria uma grande ilusão imaginar que a cada problema histórico corresponde um tipo único de documentos, específico para tal emprego. Quanto mais a pesquisa, ao contrário, se esforça por atingir os fatos profundos, menos lhe é permitido esperar a luz a não ser dos raios convergentes de testemunhos muito diversos em sua natureza. Que historiador das religiões se contentaria em compilar tratados de teologia ou coletâneas de hinos? Ele sabe muito bem que as imagens pintadas ou esculpidas nas paredes dos santuários, a disposição e o mobiliários dos túmulos têm tanto a lhe dizer sobre as crenças e as sensibilidades mortas quanto muitos escritos. Assim como o levantamento das crônicas ou dos documentos, nosso conhecimento das invasões germânicas depende da arqueologia funerária e do estudo dos nomes de lugares. À medida que nos aproximamos de nossa época, essas exigências tornam-se sem dúvida diferentes. Nem por isso se tornam menos imperiosas (BLOCH, 2001, p. 80). 
A ética em Bloch também perpassa pelo uso das fontes históricas. Todo o cuidado com a análise das fontes tem tudo para proporcionar uma pesquisa mais eficiente. $\mathrm{O}$ uso de mais de uma fonte, fontes diversificadas, que se cruzam e que possam tentar aproximar-se mais do passado estudado, assim como fez Ginzburg (2006), os indícios que levantou permitiu-nos conhecer a história e vida de um simples moleiro, apelidado de Menocchio, que nasceu em Montreale, no ano de 1532. Com fontes encontradas nos arquivos da igreja, Ginzburg aproximou-se da vida de um homem singular, que aparentemente nada tinha a contribuir para a história, no entanto, com muita responsabilidade o autor chegou a uma história complexa, de um homem que enfrentou o grande poder da igreja.

Ginzburg é um grande exemplo desses autores que foi mais fundo nas análises históricas e não se prendeu a uma simples narração de fatos, que muitas das vezes ficam distantes das pessoas comuns. E daí vem outra situação que Bloch nos chama atenção: o ídolo das origens.

Nunca é mau começar por um mea culpa. Naturalmente cara a homens que fazem do passado seu principal tema de estudos de pesquisa, a explicação do mais próximo pelo mais distante dominou nossos estudos às vezes até à hipnose. Sob sua forma mais característica, esse ídolo da tribo dos historiadores tem um nome: é a obsessão das origens (BLOCH, 2001, p. 56).

Os historiadores caíram em muitas armadilhas nas pesquisas históricas. Bloch aponta que a obsessão pela origem das coisas, como se estas explicassem tudo por si só, levou a história a um simples narrar, sem problematização e sem preocupação com os acontecimentos do passado e do presente, como ele deixa bem explícito "o estudo do passado não deve obscurecer o estudo do presente. A relação entre ambos é dinâmica" (BLOCH, 2001, p. 67).

Em suma, nunca se explica plenamente um fenômeno histórico fora do estudo de seu momento. Isso é verdade para todas as etapas da evolução. Tanto daquela em que vivemos como das outras. O provérbio árabe disse antes de nós: "Os homens se parecem mais com sua época do que com seus pais." Por não ter meditado essa sabedoria oriental, o estudo do passado às vezes caiu em descrédito $(\mathrm{BLOCH}, 2001$, p. 60). 
E assim os testemunhos do passado, as heranças que os vestígios históricos nos dão nos permitem conhecer muito mais do que imaginamos. E mais do que nunca, a frase que comumente ouvimos durante as buscas nos arquivos realizadas por jovens pesquisadores, de que: "não tem nada nesta fonte"; mostra-se para Bloch algo totalmente impossível de se ocorrer. As fontes têm mais a dizer do passado do que o próprio documento aparenta.

Em nossa inevitável subordinação em relação ao passado, ficamos [portanto] pelo menos livres no sentido de que, condenados sempre a conhecê-lo exclusivamente por meio de [seus] vestígios, conseguimos, todavia, saber sobre ele muito mais do que ele julgara sensato nos dar a conhecer. [É, pensando bem, uma grande revanche da inteligência sobre o dado.] (BLOCH, 2001, p. 78).

Também é interessante mencionar que a ética com o trabalho histórico e com o trabalho com as fontes também dependem de alguns acontecimentos externos ao pesquisador. As fontes negligenciadas, extraviadas, seja por governos, ou outros responsáveis, também são alguns dos impedimentos que impedem o pesquisador de chegar até inúmeras fontes que se perdem com o passar dos tempos.

Será assim pelo menos até que, renunciando a se entregar às suas próprias tragédias com essa disposição, as sociedades consintam enfim a organizar racionalmente, com sua memória, o conhecimento de si mesmas. Só conseguirão isso lutando corpo-a-corpo com os dois principais responsáveis pelo esquecimento e pela ignorância: a negligência, que extravia os documentos; e [, mais perigosa ainda,] a paixão pelo sigilo - sigilo diplomático, sigilo dos negócios, sigilo das famílias que os esconde ou destrói (BLOCH, 2001, p.85).

Além das fontes "perdidas", Bloch também nos chama a atenção para as fontes falsas. Documentos que trazem informações que muitas das vezes divergem com informações contidas em outros documentos. Por este motivo também é muito importante o cruzamento de fontes e suas informações, para assim se ter uma noção do que está sendo analisado. No entanto, não basta apenas identificar a informação falsa, é preciso também entender o motivo que levou a construção dessa fonte, utilizando-se do poder da dúvida.

[Mas] não basta constatar o embuste. É preciso também descobrir seus motivos. Mesmo que, a princípio, para melhor rastreá-lo. Enquanto subsistir uma dúvida sobre suas origens, 
ele permanecerá em si mesmo algo de rebelde à análise; por conseguinte, de apenas até semi-comprovado. Acima de tudo, uma mentira enquanto tal é, a seu modo, um testemunho (BLOCH, 2001, p. 98).

Este poder da dúvida permite abrir um grande leque de possibilidades para a análise histórica. O historiador não se torna fechado e tem a sua disposição, a partir das fontes, vários grupos, lados, interesses, decisões, de pessoas, de grupos políticos, entre outros, que podem determinar uma aproximação mais profunda do fato histórico.

Para isso, Bloch nos lembra o quão cuidadoso devemos ser para não julgar o passado com os valores e olhares dos dias atuais. O ser humano sempre se colocou como um juiz das coisas e nas pesquisas históricas isso não seria diferente.

Ora, por muito tempo o historiador passou por uma espécie de juiz dos Infernos, encarregado de distribuir o elogio ou o vitupério aos heróis mortos. [...] Montaigne já nos chamara a atenção: "A partir do momento em que o julgamento pende para um lado, não se pode evitar de contornar e distorcer a narração nesse viés. [...] A lição do desenvolvimento intelectual da humanidade é no entanto clara: as ciências sempre se mostraram mais fecundas e, por conseguinte, muito mais proveitosas, enfim, para a prática, na medida em que abandonavam mais deliberadamente o velho antropocentrismo do bem e do mal" (BLOCH, 2001, p. 125-27).

Esse julgamento também recai em outra importante questão: a maneira com que escolhemos olhar determinado sujeito no tempo histórico. Bloch afirma que temos um grande vício em separar o homem em vários homens e nas ciências isso pode ser prejudicial à real intenção de estudar e conhecer o ser humano. Como exemplo podemos mencionar a área da anatomia humana, preocupada em estudar o corpo humano; as ciências da religião, estudando a religiosidade; a filosofia o pensar e refletir humano, dentre outras. Cada uma sob uma ótica, sob uma metodologia, separando um ser único em vários.

A ciência decompõe o real apenas a fim de melhor observá-lo, graças a um jogo de fogos cruzados cujos raios constantemente se combinam e interpenetram. O perigo começa quando cada projetor pretende ver tudo sozinho; quando cada canto do saber é tomado por uma pátria. [...] Ora, homo religiosus, homo economicus, homo politicus, toda essa ladainha de homens em us, cuja lista poderíamos estender à vontade, evitemos tomá-los por outra coisa do que na verdade são: fantasmas cômodos, com a condição de não se tornarem um estorvo. $\mathrm{O}$ único ser de carne e osso é o homem, sem mais, que reúne ao mesmo tempo tudo isso (BLOCH, 2001, p. 131- 32). 


\section{CONSIDERAÇÕES FINAIS}

A obra de Bloch apesar de não tratar da ética propriamente dita, traz muito dela para compreensão e construção de uma nova forma de fazer história, de se produzir conhecimento. A honestidade com as fontes, o saber cruzar informações, o respeito pelas informações e pelos leitores, a preocupação civil e moral que a ciência histórica deveria ter, a preocupação em não julgar o passado com os valores do presente, entre outras questões, mostram um pesquisador preocupado com a pesquisa e com caráter sério e responsável com a história da humanidade.

E assim Bloch aponta uma série de questões que perpassam pelo campo ético das pesquisas históricas. Era de seu desejo que seus escritos pudessem contribuir com a formação daqueles que ele havia ensinado, seus alunos. A ética em Bloch não começa e termina na análise das fontes, mas alcança outros sujeitos, alunos, leitores, doutores, todos importantes e que faziam do trabalho histórico algo que valeria a pena produzir.

\section{REFERÊNCIAS}

BLOCH, Marc Leopold Benjamin. Apologia da história ou o ofício do historiador. Prefácio: Jacques Le Goff. Apresentação à edição brasileira: Lilia Moritz Schwarcz; tradução André Telles. Rio de Janeiro: Zahar, 2001.

DICIO. Conceito de Ética. Disponível em: $<$ https://www.dicio.com.br/ethos/>. Acesso em: 17 jul. 2019.

FERNANDES, Cláudio. Escola dos Annales. Disponível em:

$<$ https://www.historiadomundo.com.br/curiosidades/escola-dos-annales.htm>. Aceso em: 23 jul. 2019.

GASPARETTO JUNIOR, Antonio. Marc Bloch. Disponível em:

$<$ https://www.infoescola.com/biografias/marc-bloch/>. Acesso em: 23 jul. 2019.

GINZBURG, Carlo. O queijo e os vermes: o cotidiano e as ideias de um moleiro perseguido pela inquisição. Tradução: Maria Betânia Amoroso; Tradução dos poemas: José Paulo Paes; revisão técnica Hilário Franco Jr. São Paulo: Companhia das Letras, 2006.

LE GOFF, Jacques. Prefácio. In: BLOCH, Marc Leopold Benjamin. Apologia da história ou o ofício do historiador. Prefácio: Jacques Le Goff. Apresentação à edição brasileira: Lilia Moritz Schwarcz; tradução André Telles. Rio de Janeiro: Zahar, 2001. p. 15 - 34. 
LE GOFF, Jacques. História e Memória. Tradução: Bernardo Leitão... [et al]. $7^{\mathrm{a}}$ ed. revista. Campinas, SP: Editora da Unicamp, 2013.

MICHAELIS. Conceito de Ética. Disponível em: <http://michaelis.uol.com.br/busca?id=OmqE $>$. Acesso em: 17 jul. 2019.

PEREIRA, Edinei. Resenha do livro Apologia da história ou o ofício de historiador. Disponível em: $<$

https://www.cafecomsociologia.com/apologia-da-historia-ou-o-oficio-de-historiador-resenha/> Acesso em: 01 ago. 2019.

SCHWARCZ, Lilia Moritz. Apresentação à edição brasileira. In: BLOCH, Marc Leopold Benjamin. Apologia da história ou o ofício do historiador. Prefácio: Jacques Le Goff. Apresentação à edição brasileira: Lilia Moritz Schwarcz; tradução André Telles. Rio de Janeiro: Zahar, 2001. p. 7 - 12 . 